\title{
IMMUNE RESPONSE AND PHAGOCYTOSIS OF CHILDREN WITH STREPTOCOCCAL TONSILLITIS AND INFECTED WITH THE HERPES VIRUS TYPE 6
}

\author{
Viktoriia Olkhovska $\bowtie$ \\ Department of Pediatrics ${ }^{1}$ \\ vikaolkhov91@gmail.com \\ Olga Olkhovska \\ Department of Pediatric Infectious Diseases \\ Kharkiv National Medical University \\ 4 Nauky ave., Kharkiv, Ukraine, 61022 \\ Zalina Yeloyeva \\ Department of Pediatrics ${ }^{1}$ \\ ${ }^{1}$ Kharkiv Medical Academy of Postgraduate Education \\ 58 Amosova str., Kharkiv, Ukraine, 61176
}

$\triangle$ Corresponding author

\begin{abstract}
The aim of the work is to study the indicators of cellular and humoral immune response and FAN of patients with tonsillitis in children infected with HHV-6 type.

Materials and methods of research. In 72 children aged 3-15 years (mean age $8.42 \pm 1.44$ years), patients with streptococcal tonsillitis of moderate severity, the levels of the main subpopulations of blood lymphocytes were determined using monoclonal antibodies by solid-phase enzyme-linked immunosorbent assay, phagocytic activity of neutrophils (FAN) using the nitrosine tetrazolium reduction test (HCT test) and serum Ig A, Ig M, Ig G levels by radial immunodiffusion. The studies were carried out in the acute period and in the period of convalescence. Mathematical and statistical processing of the data obtained was carried out using Microsoft Excel 2003 and Statistica 6.0 programs. The significance of differences between the mean values was determined using the Student's test $(t)$.

Results. Different mechanisms of formation of pathological process at streptococcal tonsillitis at children depending on the concomitant HHV-6 type infection are revealed. In patients with mixed infection in the acute period of tonsillitis determine the signs of deficiency of the cellular immune system with the maximum deviation of CD-lymphocytes ( $t=3.13 \mathrm{vs}$. $t=2.16$ in mono-infection), the tension in the humoral link of the immune response Ig deviation ( $t=1.63$ against $t=0.91$ in mono-infection) on the background of phagocytosis violation in terms of FAN deviation ( $t=3.22$ against $t=2.01 \mathrm{in}$ mono-infection). By the period of convalescence, the restoration of the imbalance of specific and non-specific protection factors does not occur. Increased Ig G content in the acute period is one of the features of streptococcal tonsillitis in children on the background of HHV-6t infection.

Conclusions. Concomitant VGL-6 type infection in children with streptococcal tonsillitis affects the mechanisms of formation of the inflammatory process and the reactivity of patients, forming the preconditions for adverse outcomes of the disease. The obtained results can be the basis for early detection of herpes virus infection in patients with tonsillitis, will help to optimize the management of patients in different periods of the disease.
\end{abstract}

Keywords: streptococcal tonsillitis, herpes virus type 6, phagocytosis, cellular immunity, immunoglobulins.

DOI: $10.21303 / 2504-5679.2021 .002098$

\section{Introduction}

Streptococcal infection has long been a relevant pathology, especially among children $[1,2]$. The consequences of tonsillitis caused by hemolytic streptococcus, which often turn into a chronic form, are the development of infectious-allergic and immune-mediated pathology, which include diseases of the cardiovascular system, connective tissue, kidneys [3, 4].

At the current stage of development of medicine in the practice of health care comorbid conditions are increasingly common, a combination of two or more pathogens that definitely affect 
each other, can lead to changes in the clinical course and outcome of the disease. The twenty-first century is called the «century of viruses», and not only because of the new coronaviruses, but also because of the widespread spread of herpes viruses. Infection of the latter occurs in early childhood. Persistence of herpes viruses is one of the factors of frequent «respiratory» diseases, affects the formation of protective systems of the child's body $[5,6]$.

One of the viruses of the herpes group is the human virus type $6(\mathrm{HHV}-6)$, which among all other viruses is the least studied, can cause damage to immune cells, lymphatic systems, internal organs [7,8].

The course and outcomes of the disease, complete recovery in bacterial pathology, including streptococcal tonsillitis, are largely due to the timely and adequate response of specific and nonspecific protective factors, which include the state of cellular and humoral immune response and phagocytic activity of neutrophils (FAN) [9].

In our opinion, it is in the period of early convalescence of streptococcal tonsillitis that pathological factors are formed, which in the future can lead to incomplete recovery, the impossibility of timely rehabilitation of the organism from the pathogen, the formation of various somatic pathologies. Unfortunately, in the sources available to us, we did not find information on specific (indicators of cellular and humoral immunity) and non-specific (FAN) protective factors in tonsillitis of streptococcal etiology in children infected with HHV-6 type.

Therefore, the aim of the study was to study the indicators of cellular and humoral immune response and FAN of patients with tonsillitis in children infected with HHV-6 type.

\section{Materials and methods of the research}

During 2018-2021 on the basis of the non-profit municipal institution «Regional Children's Infectious Diseases Hospital» in Kharkiv, a survey of 72 children aged 3-15 years (mean age $8.42 \pm 1.44$ years), patients with tonsillitis of streptococcal etiology of moderate severity, which was divided into two groups. The first group included 33 patients with tonsillitis and infected with HHV-6 (mixed infection), the second - 39 children with tonsillitis without concomitant infection (mono-infection). Verification of the diagnosis was performed according to clinical and anamnestic data, the results of bacteriological, virological and serological tests in accordance with ICD-10. HHV-6 - infection was diagnosed by high titers of Ig G antibodies to HHV-6 with negative PCR results to HHV-6 in serum and saliva (latent form). Children in both observation groups were the same age $(7.41 \pm 2.95$ and $9.87 \pm 2.44$ years, $p>0.05$ ), and the sex of patients was comparable. Determination of the cellular component of the immune response was performed on the levels of subpopulations of lymphocytes $\mathrm{CD} 3+, \mathrm{CD} 4+, \mathrm{CD} 8+, \mathrm{CD} 16+, \mathrm{CD} 22+$ and $\mathrm{CD} 25+$ peripheral blood of patients using monoclonal antibodies by solid-phase enzyme-linked immunosorbent assay. FAN of peripheral blood was determined using the nitrosine tetrazolium reduction test (NTR test). Spontaneous NTR test (NTR sp) and stimulated NTR test were determined during the FAN study. The state of the humoral part of the immune response was determined by the levels of serum Ig A, Ig M, Ig G by radial immunodiffusion.

The work was carried out in accordance with the principles of the Declaration of Helsinki adopted by the General Assembly of the World Medical Association (1964-2000), the Council of Europe Convention on Human Rights and Biomedicine (1997), relevant WHO provisions, the International Council of Medical Societies, the International Medical Code ethics (1983) and laws of Ukraine.

Informed consent was obtained from the parents of all patients who participated in the study. The Committee of the Bioethics Commission approved and confirmed the protocol No. 3 dated 18.10.2018.

The control group consisted of 20 healthy children, similar in age and sex. Mathematical and statistical processing of the data obtained was carried out using Microsoft Excel 2003 and Statistica 6.0 programs. The significance of differences between the mean values was determined using the Student's test $(t)$. The assessment of the reliability of the correlation coefficient was carried out according to standard tables.

\section{Research results}

The study of the indicators was carried out in the acute period (1-2 days of illness) and in the period of convalescence (7-10 days of illness). The obtained results are given in the Table 1 . 
Table 1

Indicators of immune response and phagocytic activity of neutrophils in children with tonsillitis, $(\mathrm{M} \pm \mathrm{m})$

\begin{tabular}{|c|c|c|c|c|}
\hline Indicators & Period & The first group $(n=34)$ & The second group $(n=40)$ & Control $(n=20)$ \\
\hline \multirow{2}{*}{$\mathrm{CD} 4^{+}, \%$} & acute & $26.22 \pm 1.93^{1,2}$ & $33.05 \pm 1.07^{1}$ & \multirow{2}{*}{$37.31 \pm 0.72$} \\
\hline & convalescence & $33.28 \pm 0.79^{1}$ & $36.11 \pm 1.04^{2}$ & \\
\hline \multirow{2}{*}{$\mathrm{CD} 8^{+}, \%$} & acute & $20.15 \pm 0.97^{1}$ & $24.48 \pm 1.12^{2}$ & \multirow{2}{*}{$26.83 \pm 0.54$} \\
\hline & convalescence & $23.55 \pm 1.02^{1}$ & $28.08 \pm 1.14^{2}$ & \\
\hline \multirow{2}{*}{$\mathrm{CD} 16^{+}, \%$} & acute & $15.01 \pm 0.51^{1,2}$ & $17.17 \pm 0.54^{1}$ & \multirow{2}{*}{$12.25 \pm 1.24$} \\
\hline & convalescence & $16.17 \pm 0.94^{1}$ & $14.24 \pm 0.81$ & \\
\hline \multirow{2}{*}{$\mathrm{CD} 22^{+}, \%$} & acute & $16.08 \pm 0.85^{2}$ & $18.61 \pm 0.90^{1}$ & \multirow{2}{*}{$15.08 \pm 1.07$} \\
\hline & convalescence & $17.52 \pm 0.66^{2}$ & $20.76 \pm 1.15^{1}$ & \\
\hline \multirow{2}{*}{$\mathrm{CD} 25^{+}, \%$} & acute & $16.16 \pm 0.77$ & $16.83 \pm 1.05$ & \multirow{2}{*}{$14.51 \pm 0.85$} \\
\hline & convalescence & $17.28 \pm 1.13^{2}$ & $20.85 \pm 0.81^{1}$ & \\
\hline \multirow{2}{*}{ NTR sp, \% } & acute & $25.31 \pm 0.95^{1,2}$ & $29.04 \pm 1.07^{1}$ & \multirow{2}{*}{$19.18 \pm 2.08$} \\
\hline & convalescence & $23.81 \pm 0.74^{1}$ & $22.06 \pm 1.08$ & \\
\hline \multirow{2}{*}{ NTR st, $\%$} & acute & $38.11 \pm 0.92^{2}$ & $42.62 \pm 1.58^{1}$ & \multirow{2}{*}{$35.05 \pm 2.09$} \\
\hline & convalescence & $33.87 \pm 0.57^{2}$ & $36.14 \pm 0.76$ & \\
\hline \multirow{2}{*}{ Ig M, g/l } & acute & $1.79 \pm 0.31$ & $1.55 \pm 0.43$ & \multirow{2}{*}{$1.02 \pm 0.23$} \\
\hline & convalescence & $2.49 \pm 0.24^{1}$ & $2.04 \pm 0.37^{1}$ & \\
\hline \multirow{2}{*}{ Ig G, g/l } & acute & $11.57 \pm 0.75^{1}$ & $9.82 \pm 0.41$ & \multirow{2}{*}{$9.22 \pm 0.57$} \\
\hline & convalescence & $12.86 \pm 0.48^{1}$ & $11.08 \pm 0.32^{1,2}$ & \\
\hline \multirow{2}{*}{$\operatorname{Ig} \mathrm{A}, \mathrm{g} / 1$} & acute & $2.18 \pm 0.49$ & $2.08 \pm 0.72$ & \multirow{2}{*}{$1.48 \pm 0.24$} \\
\hline & convalescence & $2.93 \pm 0.25^{1}$ & $2.48 \pm 0.44$ & \\
\hline
\end{tabular}

Note: ${ }^{1}$ - the probability of the sign to the control group; ${ }^{2}$ - the probability of the sign between the first and second groups

Acute period of streptococcal tonsillitis is accompanied by transient deficiency of cellular immunity in all patients, as evidenced by reduced CD4+ and CD8+ lymphocytes $(p<0.05)$. These changes were most pronounced in patients with mixed infection. An increase in the content of CD16+ - lymphocytes $(p<0.05)$ was recorded, while in patients with mono-infection the levels of CD16 + cells differed not only from the control group $(p<0.01)$, but also from patients of the first group $(p<0.01)$. In contrast to patients with mixed infection, mono-infection was determined by a probable increase in the content of CD22+ $(p<0.05)$. The content of CD25+ cells increased in patients of both groups, but this increase was not significant $(p>0.05)$. In the acute period, FAN suppression was detected in patients with mixed infection, as evidenced by a less significant increase in the rate of NTR sp compared with the second group $(p<0.05)$ with a decrease in the metabolic potential of neutrophils in terms of NTR st. The latter indicator did not differ significantly from that of healthy children $(p>0.05)$. The peculiarity of the response of humoral immunity of patients was an increase in all classes of immunoglobulins (Ig), but only an increase in Ig G in patients of the first group $(p<0.05)$.

In the acute period in patients with mixed infection, the maximum degrees of deviations were found for CD lymphocytes ( $t=3.13$ vs. $t=2.16$ in mono-infection) and Ig ( $t=1.63$ vs. $t=0.91)$, and in patients with mono-infection recorded a more pronounced response of FAN ( $t=3.22$ vs. $t=2.01)$.

It was found that in the period of early convalescence in children with mixed infection there is no normalization of the content of CD4+, CD8+ and CD16 + blood lymphocytes $(p<0.05)$, while in children with mono-infection these indicators were close to normal $(p>0,05)$. Until the convalescence period, there is a significant difference in the indicator of CD22+ lymphocytes between the observation groups $(p<0.05)$. In mono-infection, this indicator was probably higher than normal $(p<0.01)$. In the dynamics of the disease levels of CD25+ cells increased. In patients with mono-infection, this indicator differed from the control group $(p<0.001)$ and from patients with mixed infection $(p<0.05)$. During the convalescence period, patients with mixed infection did not 
have a complete recovery of FAN: NTR sp values differed significantly from normal $(p<0.05)$, and NTR st parameters significantly differed from patients of the second group $(p<0.05)$. The Ig content of all classes increased in both groups by the period of convalescence. The concentration of Ig M increased, which significantly differed from the norm in all patients $(p<0.05)$. Significantly high Ig G indices were recorded in both groups, both in comparison to the control group $(p<0.01)$ and between groups $(p<0.05)$. The increase in Ig A content was significant only in patients of the first group $(p<0.05)$, and in patients with mono-infection, this figure did not differ significantly from the control group $(p>0.05)$.

In the period of convalescence in patients with mono-infection showed moderate degrees of deviation of $\operatorname{Ig}(t=2.25)$ and FAN $(t=0.86)$ with maximum fluctuations of CD lymphocytes $(t=3.05)$. The total degree of deviation was $t=2.05$. In patients with mixed infection, the maximum degrees of Ig deviation $(t=4.50)$ were recorded with moderate deviations of CD lymphocytes $(t=2.58)$ and FAN values $(t=1.35)$. The total degree of deviation in these patients was equal to $t=2.81$.

\section{Discussion}

The study revealed signs of transient suppression of the cellular immune response in children with streptococcal tonsillitis, and this suppression was exacerbated in patients with concomitant HHV-6 infection. During the period of convalescence in these children there is no complete recovery of cellular immunity: the content of CD4+, CD8+ remains reduced against the background of maintaining an increased concentration of $\mathrm{CD} 16+$. The latter are known to play a significant role in cleansing the body of pathogens $[10,11]$. Thus, the response of natural killers occurs in overstrain, which may indicate incomplete rehabilitation of the body. In our opinion, the content of CD16+ cells in the period of convalescence in patients with mixed infection could be used as one of the indicators of complete recovery of the patient. On the other hand, it is determined that the deficiency of natural killers in infected with HHV-6 increases the risk of severe brain damage [12, 13], therefore, this issue needs further study. The absence of significant fluctuations in the content of CD22+ and CD25+ cells in patients with mixed infection in the dynamics of the disease indicates the tension in the humoral part of the immune system, as indicated by other authors [14]. At the same time, the imbalance of the immune response can create conditions for further chronicity, complications, which must be taken into account in the stages of convalescence of streptococcal tonsillitis in order to prevent the development of damage to the heart, joints, kidneys $[15,16]$

Factors that create the conditions for the adverse effects of streptococcal tonsillitis include our identified FAN disorders in patients with concomitant viral herpes infection. Unfortunately, until the period of convalescence in these patients there are signs of violation of the FAN with the depletion of the functional reserve of their bactericidal properties. It is known that neutrophils are a major component of non-specific mechanisms of protection against bacterial factors. Our data coincide with the results of the study of the state of FAN in both bacterial and viral lesions [17, 18].

The changes in Ig blood parameters detected by us confirmed the increase in Ig M content inherent in the inflammatory process in all patients in the dynamics of the disease. At the same time, in our opinion, the high content of $\mathrm{Ig} \mathrm{G}$ in patients with mixed infection in the acute period of streptococcal tonsillitis is a feature of the response of such patients. This fact can be used for early diagnosis of concomitant VGL-6 infection in children with tonsillitis. The study of the properties of Ig G in streptococcal infection is important in terms of the identified opportunities to avoid the pathogen from the immune response [19].

Thus, the presence of concomitant VGL-6 type of infection significantly affects the course of streptococcal tonsillitis in children, leads to changes in specific and nonspecific defence mechanisms, can create conditions for adverse course of tonsillitis, chronic streptococcal infection, somatic pathology [20, 21].

Study limitations. Congenital or acquired immunodecytic conditions in children, longterm use of corticosteroids and cytostatics.

Prospects for further study. The obtained results can be used for early detection of infection of patients with herpes virus, methods of treatment of patients in different periods of the disease. 


\section{Conclusions}

1. Infection with HHV-6 type in children with streptococcal tonsillitis has a negative effect on specific and specific protective mechanisms of the body.

2. Different mechanisms of formation of inflammatory process depending on presence of VGL-6 infection are revealed. In the acute period in patients with mixed infection revealed the maximum degree of deviation of CD-lymphocytes ( $t=3.13$ vs. $t=2.16$ in mono-infection) and $\operatorname{Ig}(t=1.63$ vs. $t=0.91)$, and in patients with mono-infection recorded a more pronounced response of FAN $(t=3.22$ vs. $t=2.01)$.

3 . In the period of convalescence in patients with mono-infection showed moderate degrees of deviation of $\operatorname{Ig}(t=2.25)$ and FAN $(t=0.86)$ with maximum fluctuations of CD lymphocytes $(t=3.05)$. In patients with mixed infection, the maximum degrees of $\operatorname{Ig}$ deviation $(t=4.50)$ were recorded with moderate deviations of CD lymphocytes $(t=2.58)$ and FAN values $(t=1.35)$.

4. The course of streptococcal tonsillitis in children with concomitant HHV-6 type infection occurs against the background of an imbalance in the functioning of the cellular and humoral links of the immune response, a violation of the phagocytic activity of neutrophils, which persist until the period of convalescence and can lead to unfavourable outcomes.

\section{Conflict of interests}

The authors declare that they have no conflicts of interest.

\section{Financing}

The study was performed without financial support.

\section{References}

[1] Carapetis, J. R., Beaton, A. (2016). Acute rheumatic fever and rheumatic heart disease. Nature Reviews. Disease Primers, 2, 15084. doi: http://doi.org/10.1038/nrdp.2015.85

[2] Valderrama, J. A., Nizet, V. (2018). Group A Streptococcus encounters with host macrophages. Future Microbiology, 13 (1), 119-134. doi: http://doi.org/10.2217/fmb-2017-0142

[3] Walker, M. J., Barnett, T. C., McArthur, J. D., Cole, J. N., Gillen, C. M., Henningham, A. et. al. (2014). Disease Manifestations and Pathogenic Mechanisms of Group A Streptococcus. Clinical Microbiology Reviews, 27 (2), 264-301. doi: http://doi.org/ 10.1128/cmr.00101-13

[4] Bennett, J., Moreland, N. J., Oliver, J., Crane, J., Williamson, D. A., Sika-Paotonu, D. et. al. (2019). Understanding group A streptococcal pharyngitis and skin infections as causes of rheumatic fever: protocol for a prospective disease incidence study. BMC Infectious Diseases, 19 (1). doi: http://doi.org/10.1186/s12879-019-4126-9

[5] Kramarov, S. O., Yevtushenko, V. V. (2019). Modern approaches to the treatment of herpetic infection in children. Actual Infectology, 7 (3), 144-149. doi: http://doi.org/10.22141/2312-413x.7.3.2019.170993

[6] Hyliuk, O. H., Bulat, L. M. (2017). Children age clinical peculiarities of herpes infections. Biomedical and biosocial anthropology, 28, 112-116.

[7] Cohen, J. I. (2015). Human Herpesvirus Types 6 and 7 (Exanthem Subitum). Mandell, Douglas, and Bennett's Principles and Practice of Infectious Diseases, 1772-1776.e1. doi: http://doi.org/10.1016/b978-1-4557-4801-3.00142-9

[8] Das, B., Reddy, S., Eliassen, E., Krueger, G. (2017). Human herpesvirus 6-induced inflammatory cardiomyopathy in immunocompetent children. Annals of Pediatric Cardiology, 10 (3), 259. doi: http://doi.org/10.4103/apc.apc_54_17

[9] Gavrylenko, I., Laiko, A., Karas, A., Karas, H. (2018). Cytochemical examination of blood cells of children with chronic tonsillitis and type 1 diabetes mellitus. ScienceRise: Medical Science, 3 (23), 13-17. doi: http://doi.org/10.15587/2519-4798.2018.127424

[10] Eliassen, E., Di Luca, D., Rizzo, R., Barao, I. (2017). The Interplay between Natural Killer Cells and Human Herpesvirus-6. Viruses, 9 (12), 367. doi: http://doi.org/10.3390/v9120367

[11] Hanson, D. J., Hill, J. A., Koelle, D. M. (2018). Advances in the Characterization of the T-Cell Response to Human Herpesvirus-6. Frontiers in Immunology, 9. doi: http://doi.org/10.3389/fimmu.2018.01454

[12] Rasskazova, O. M., Rybak, I. R., Vorozhko, T. A., Ponomarenko, V. V., Maltsev, D. V. (2017). Chronic viral infection caused by the herpes virus type 6, with a damage of the nervous system against the background of a deficiency of natural killers. Klinichna imunolohiia. Alerholohiia. Infektolohiia, 5 (102), 27-33.

[13] You, S. J. (2019). Human Herpesvirus-6 may be Neurologically Injurious in Some Immunocompetent Children. Journal of Child Neurology, 35 (2), 132-136. doi: http://doi.org/10.1177/0883073819879284 
[14] Galich, E. N., Solovyeva, I. L., Kuselman, A. I., Solovyeva, A. A. et. al. (2019). Phagocytosis and Antibody Mediated Immunity in Children Infected with Human Herpes Virus 6. Doctor.Ru, 160 (5), 23-26. doi: http://doi.org/10.31550/1727-23782019-160-5-23-26

[15] Coffey, P. M., Ralph, A. P., Krause, V. L. (2018). The role of social determinants of health in the risk and prevention of group A streptococcal infection, acute rheumatic fever and rheumatic heart disease: A systematic review. PLOS Neglected Tropical Diseases, 12 (6), e0006577. doi: http://doi.org/10.1371/journal.pntd.0006577

[16] Nayiga, I., Okello, E., Lwabi, P., Ndeezi, G. (2017). Prevalence of group a streptococcus pharyngeal carriage and clinical manifestations in school children aged 5-15 yrs in Wakiso District, Uganda. BMC Infectious Diseases, 17 (1). doi: http://doi.org/10.1186/s12879-017-2353-5

[17] Salimzianova, T. E. (2016). Perevarivaiuschaia aktivnost fagotsitov kak kriterii nespetsificheskoi reaktivnosti organizma. Sovremennye nauchnye issledovaniia i razrabotki, 7, 480-482.

[18] Kurchenko, I. F., Svidro, S. V., Savchenko, V. S. (2016). Vplyv Esberitoksu in vitro na mononukleary peryferychnoi krovi khvorykh na herpesvirusnu infektsiiu. Imunolohiia ta alerholohiia: nauka i praktyka, 1-4, 19-25.

[19] Naegeli, A., Bratanis, E., Karlsson, C., Shannon, O., Kalluru, R., Linder, A. et. al. (2019). Streptococcus pyogenes evades adaptive immunity through specific Ig G glycan hydrolysis. Journal of Experimental Medicine, 216 (7), $1615-1629$. doi: http://doi.org/10.1084/jem.20190293

[20] Balasubramanian, R., Marks, S. D. (2017). Post-infectious glomerulonephritis. Paediatrics and International Child Health, 37 (4), 240-247. doi: http://doi.org/10.1080/20469047.2017.1369642

[21] Gupta, A., Bhalla, K., Bhardwaj, P., Mehra, S., Nehra, D., Nanda, S. (2019). Role of epidemiological risk factors in improving the clinical diagnosis of streptococcal sore throat in pediatric clinical practice. Journal of Family Medicine and Primary Care, 8 (10), 3130. doi: http://doi.org/10.4103/jfmpc.jfmpc_495_19

Received date 19.08.2021

Accepted date 23.09.2021

Published date 30.09.2021
(C) The Author(s) 2021

This is an open access article under the Creative Commons CC BY license

How to cite: Viktoriia, O., Olga, O., Zalina, Y. (2021). Immune response and phagocytosis of children with streptococcal tonsillitis and infected with the herpes virus type 6. EUREKA: Health Sciences, 5, 41-46. doi: http://doi.org/10.21303/ 2504-5679.2021.002098 